\title{
DOGMÁTICA DE LOS DERECHOS FUNDAMENTALES Y TRANSFORMACIONES DEL SISTEMA CONSTITUCIONAL
}

\author{
ANTONIO-ENRIQUE PÉREZ LUÑO \\ Catedrático de Filosofía del Derecho \\ Universidad de Sevilla
}

\section{SUMARIO}

I. Planteamiento: la teoría pura del derecho y su actual revisión.

II. El sistema constitucional de los derechos fundamentales desde la teoría del derecho.

III. Conclusión: transformaciones del sistema de los derechos fundamentales y crisis del positivismo jurídico.

\section{PLANTEAMIENTO: LA TEORÍA PURA DEL DERECHO Y SU ACTUAL REVISIÓN}

En el curso de estos últimos años se advierte la preocupación de los estudiosos e investigadores del pensamiento de Hans Kelsen, pertenecientes a distintas áreas geográficas y culturas jurídicas, por mantener indemne el legado doctrinal kelseniano frente al "asedio" científico de determinadas concepciones contemporáneas, especialmente influyentes en los desarrollos de la teoría y la filosofía jurídica (Hart, Rawls, Habermas, Dworkin, Alexy, Häberle...).

Tengo para mí que esas alarmas y esa inquietud obsesiva por defender la teoría pura respecto a doctrinas y posturas teóricas y/o metodológicas sobre el derecho, responde a un error de enfoque. La teoría pura del derecho elaborada por Hans Kelsen es un modelo de coherencia interna y, por tanto, resulta difícilmente atacable desde el interior de las premisas en las que se expresa su fundamento y desarrollo. Por eso, las doctrinas filosóficas y jurídicas que han cuestionado y cuestionan la teoría de Kelsen resultan poco eficaces y 
convincentes cuando pretenden desvirtuarla "desde dentro"; es decir, desde los propios postulados informadores de sus tesis y desde las inferencias que de ellos dimanan.

Los herederos teóricos de Kelsen se hallan absortos en construir un baluarte especulativo capaz de resistir la confrontación intelectual con las concepciones jurídicas actuales, que reputan opuestas o, en su caso, revisionistas del legado científico del maestro vienés. Personalmente, no puedo convenir con lo que esa estrategia representa. A mi entender, el riesgo de revisión superadora de la teoría pura del derecho no reside en las eventuales críticas que frente a ella directamente se avanzan, sino en las nuevas coordenadas a las que responden los sistemas jurídicos actuales y de las que las nuevas concepciones jurídicas se hacen cargo con mayor precisión y adecuación que la teoría pura del derecho.

La teoría pura del derecho se presentaba y justificaba a sí misma como una teoría explicativa del derecho positivo. Como quiera que el ordenamiento jurídico de los Estados de derecho contemporáneos ha experimentado una importante transformación en su sistema de fuentes ${ }^{1}$, así como en sus postulados fundamentadores, hoy se precisa de nuevos marcos teóricos y paradigmas metodológicos capaces de dar cuenta de esa nueva situación.

Las reflexiones que a continuación se avanzan, tienen el propósito de hacerse eco de esa metamorfosis operada en los ordenamientos jurídicos, con especial atención a sus repercusiones en el sistema de los derechos fundamentales.

\section{EL SISTEMA CONSTITUCIONAL DE LOS DERECHOS FUNDAMENTALES DESDE LA TEORÍA DEL DERECHO}

En la estructura normativa de las Constituciones se advierten los estímulos de la cultura jurídica de su tiempo. El sistema de los derechos fundamentales, que define la parte dogmática de las Constituciones de los Estados de derecho, se advierten esas influencias teóricas. En el diseño constitucional de esa materia se reflejan algunas de las concepciones doctrinales del sistema jurídico más influyentes en el momento de su gestación. De ello se infiere que, en el constitucionalismo de las últimas décadas, hayan hallado eco algunas de las concepciones jurídicas más relevantes e influyentes de ese periodo.

La célebre Teoría del ordenamiento jurídico elaborada por Santi Romano (1918, se cita por la ed. de 1963), la dimensión nomo-dinámica del orden jurídico planteada por Hans Kelsen en la segunda edición de su Teoría pura del derecho (1960), así como la certera síntesis de ambas concepciones debida a Norberto Bobbio (1960), constituyen fuentes insoslayables para el análisis y la

1 PÉREZ LUÑO, A.E., El desbordamiento de las fuentes del derecho, Real Academia Sevillana de Legislación y Jurisprudencia, Sevilla, 1993. 
comprensión de la idea del sistema de los derechos fundamentales diseñado en el constitucionalismo vigente en el inmediato pasado ${ }^{2}$.

En el volumen monográfico sobre Los derechos fundamentales ${ }^{3}$, tuve ocasión de ocuparme de algunos aspectos básicos de la formación del concepto de sistema en la ciencia jurídica contemporánea, de las relaciones entre los conceptos de sistema y ordenamiento jurídico, de la distinción entre los aspectos extrínsecos e intrínsecos de los sistemas constitucionales, así como del debate doctrinal entre el monismo y el pluralismo como rasgos definitorios de los ordenamientos jurídicos. Sería ocioso reiterar lo ya expuesto. No obstante, sí parece oportuno aludir a los rasgos constitutivos de los sistemas de derechos fundamentales, así como a las metamorfosis operadas en esa categoría constitucional en los últimos años.

Aludir a un sistema constitucional de los derechos fundamentales sugiere, de inmediato, la cuestión de la interdependencia o mutua implicación existente entre tales derechos; ya que la unidad de sentido no aparece como una cualidad de las singulares formulaciones normativas de cada uno de los derechos fundamentales, sino como una característica de todos ellos en cuanto conjunto.

El tema de la interconexión orgánica y finalista de los derechos fundamentales, es decir, su dimensión sistemática, ha suscitado un interés creciente en la dogmática constitucional de los últimos años. No en vano, el proceso de sistematización de los materiales normativos es un fenómeno paralelo al de la formación del Estado moderno, que ha ido adquiriendo progresiva importancia en la medida en que ha crecido el número y complejidad de las reglas integrantes del derecho positivo estatal. De ahí que precisamente la sistematicidad sea uno de los rasgos definitorios de los ordenamientos jurídicos más evolucionados, en los que opera como una garantía de la seguridad jurídica. En efecto, la sistematicidad permite un conocimiento, interpretación y consiguiente aplicación del derecho, fundada en criterios precisos y rigurosos, antes que en el arbitrio o en el azar.

Esta idea de orden y regularidad, que irradia del conjunto normativo para proyectarse en sus partes integrantes, es la que permite concebir los derechos y libertades constitucionales como un sistema y, de este modo, abordar su proceso hermenéutico como búsqueda del sistema, o unidad de sentido sistemático, de las normas singulares formuladoras de cada derecho fundamental.

El Tribunal Constitucional español al igual que las principales jurisdicciones constitucionales de nuestro entorno, ha subrayado este aspecto al recor-

2 AGUIAR DE LUQUE, L., Democracia directa y Estado constitucional, EDERSA, Madrid, 1977; AlZAGA VIllaAmIL, O., Derecho Político español según la Constitución de 1978, EDERSA, Madrid, 1996.

3 PÉREZ LUÑO, A.E., Los derechos fundamentales, Tecnos, Madrid, 1984 (8. ${ }^{a}$ ed.2004), pp. 137 y ss.

4 PÉREZ LUÑO, A.E., Derechos humanos, Estado de Derecho y Constitución, 2003, pp. 268 y ss y 295 y ss.: PÉREZ LUÑO, Antonio-Erique. Los derechos fundamentales, cit., pp. 137 y ss. 
dar que la interpretación del alcance y contenido de los derechos fundamentales "ha de hacerse considerando la Constitución como un todo en el que cada precepto encuentra su sentido pleno valorándolo en relación con los demás, es decir, de acuerdo con una interpretación sistemática" (STC 5/1983, FJ 3).

Doctrina corroborada en una decisión posterior en la que, con referencia a un dato clave en la unidad de sentido de los derechos fundamentales -el de su contenido esencial—, indica que tal contenido "puede extraerse en parte de la propia Constitución, interpretada de forma sistemática, dado que la misma es un todo en el que cada precepto adquiere su pleno valor y sentido en relación a los demás” (STC 67/ 1984, FJ 2).

El reconocimiento explícito, por parte de nuestra más elevada instancia jurisdiccional constitucional, del carácter "Sistemático" de nuestra tabla de derechos fundamentales deja abierta la consideración de importantes cuestiones.

En primer término, suscita el tema de la relación entre la idea de sistema constitucional y la noción de ordenamiento jurídico, expresada también en el propio texto de la Constitución. En efecto, la Ley Superior de 1978, a diferencia de los documentos precedentes de nuestra historia constitucional, utiliza literalmente el término "ordenamiento jurídico" en los artículos: 1.1, al enumerar los valores superiores del "ordenamiento jurídico»; 9.1, cuando establece el sometimiento de los ciudadanos y los poderes públicos a la Constitución y al resto del "ordenamiento jurídico"; 96.1, donde prescribe que los tratados internacionales válidamente celebrados, una vez publicados oficialmente en España, formarán parte del "ordenamiento interno", y 147.1, al señalar que los Estatutos de las Comunidades Autónomas son parte integrante del "ordenamiento jurídico" estatal.

La alusión explícita de nuestra Constitución al concepto de ordenamiento jurídico no puede considerarse como una figura retórica o un dato casual, sino que responde a las exigencias de funcionamiento del derecho en una sociedad técnicamente avanzada. La Constitución española, como norma suprema de un Estado de derecho desarrollado, al apelar a la noción de ordenamiento jurídico no hace sino reconocer que el conjunto de reglas que integran su Derecho positivo objetivo responde a los principios básicos de: unidad, plenitud y coherencia.

a) Unidad, en cuanto que su estructura constituye un todo único, claramente delimitado y específico, cuyas características informan y se manifiestan en cada uno de los elementos que lo integran: las normas se definen a partir de su pertenencia al ordenamiento jurídico, no el ordenamiento en función de las distintas normas singulares que lo componen. Ello conduce a postular que todo ordenamiento jurídico posee una norma o regla fundamental que lo identifica, y que orienta y dirige la interpretación y aplicación de las normas singulares que lo integran. En nuestro ordenamiento jurídico la Constitución asume el papel de norma fundamental y en su seno aparecen como la cúspide de la estructura jerárquica del sistema el conjunto de los valores, principios y derechos fundamentales, a tenor de cuanto se desprende de los artículos 1.1 y 10. 1 , del propio texto constitucional. 
b) Plenitud, ya que todo ordenamiento jurídico aspira a ser una estructura completa, en el sentido de ser autosuficiente para regular todos los supuestos que se susciten en su seno, siempre que posean relevancia jurídica. El estatuto constitucional de los derechos fundamentales se presenta como un sistema pleno, en cuanto que pretende responder a todas las exigencias o necesidades básicas personales y colectivas de nuestra coyuntura histórica. Esa vocación de plenitud se manifiesta en cláusulas tales como la postulada en el artículo 10.1, donde se alude al pleno desarrollo de la personalidad, en la que la jurisprudencia y doctrina germanas (a través de la freie Entfaltung der Persönlichkeit reconocida en el art.2.1 de la Grundgestz) han visto una cláusula de garantía del sistema de los derechos fundamentales, que posibilita su adaptación a los fluctuantes valores y necesidades que emergen de la consciencia social.

c) Coberencia, esto es, la tendencia de todo ordenamiento jurídico a conformarse como un todo ordenado: un conjunto de elementos entre los que se da un orden sistemático. Si la unidad del ordenamiento jurídico se dirige a definir sus señas de identidad, y la plenitud a evitar las posibles lagunas de su estructura, la coherencia se orienta a eliminar las antinomias o contradicciones que pueden surgir en su seno. Por ello, el sistema constitucional de los derechos fundamentales, en cuanto supone la suprema expresión del orden axiológico de la comunidad, proyecta su unidad de sentido al resto del sistema normativo, siendo el postulado-guía hermenéutico de todo el ordenamiento jurídico y político, al tiempo que religa la constitución formal con la constitución material.

En estos últimos años, se ha producido una tendencia orientada a matizar el sentido de estas notas constitutivas del ordenamiento jurídico y el consiguiente desplazamiento de las mismas hacia nuevas categorías, que expresan los nuevos rumbos de la dimensión sistemática de los derechos fundamentales. Conviene apuntar aquí, por su actualidad y como anticipo a proyecciones futuras, una breve referencia a ese fenómeno.

\section{DesDe la UNIDAD AL PLURALismo}

Uno de los signos más relevantes de la coyuntura presente de los sistemas de derechos fundamentales en el constitucionalismo democrático, ha sido el desplazamiento de su centro de gravedad desde el postulado de su carácter unitario al de su significado pluralista.

Es probable que haya sido Peter Häberle el constitucionalista más atento a captar y expresar esa nueva condición del sistema de las libertades. Esta multiplicidad dentro de facetas se nutre de todo un amplio abanico de procedimientos formalmente bien diferenciados y con distintos grados respecto de su efectividad.

En su obra Pluralismo y Constitución. Estudios de Teoría Constitucional de la sociedad abierta, define certeramente los elementos conformadores de 
esa instancia pluralista hacia la que ahora se orienta el sistema de los derechos fundamentales y su consiguiente interpretación. El modelo de pluralismo que postula Häberle se manifiesta como: «multiplicidad de ideas e intereses, o viceversa, en el seno de una determinada comunidad política, dentro de los parámetros del aquí y ahora. Esta multiplicidad de facetas se nutre de todo un amplio abanico de procedimientos formalmente bien diferenciados y con diferentes grados respecto de su efectividad". Ese conjunto de ideas hace referencia a supuestos fácticos y a valores, concretándose en situaciones de consenso o de conflicto en el seno de las sociedades democráticas. La tensión dialéctica permanente en la que se desenvuelven estos fenómenos e ideas, conduce a determinadas alternativas. El pluralismo implica básicamente la "apertura" del sistema constitucional: "sus teorías y doctrinas, sus interpretaciones e intérpretes — sobre todo a nivel de derechos fundamentales-, y su inherente dogmática jurídica, junto con su posterior desarrollo y progresos "s.

En el sistema constitucional de los derechos fundamentales español se advierten manifestaciones de esas tendencias contrapuestas representadas por los principios de unidad y pluralismo.

1. De un lado, se desprende de la CE que nuestros derechos fundamentales constituyen un sistema de valores objetivos dotados de una unidad de sentido y que representan la suprema expresión del orden axiológico de nuestra sociedad, así como también de la comunidad internacional a la que pertenecemos. La existencia de esa unidad de sentido es la que explica la razón de ser de la solemne afirmación constitucional de la dignidad de la persona, en el propio quicio del Título I. Una unidad de sentido que, a continuación, se reitera con la exigencia de que los derechos y libertades constitucionales sean interpretados de conformidad con la Declaración Universal de Derechos Humanos de la ONU y los tratados y acuerdos internacionales suscritos por España, en materia de derechos fundamentales. Unidad que se refleja también en el reconocimiento constitucional de un contenido esencial de los derechos fundamentales, lo que supone aceptar que éstos poseen un núcleo previo cuya objetividad deberá respetar el propio legislador (estas tesis han hallado amplio eco en la jurisprudencia constitucional, vid., por ejemplo, las SSTC 11/1981; 13/1984: 196/1987; 71/1994...).

2) Pero, junto a esa unidad básica, nuestro orden axiológico constitucional responde a una estructura abierta y dinámica, corolario del pluralismo político, consagrado también en nuestra Ley de leyes como valor superior de nuestro ordenamiento jurídico. Nuestro estatuto de derechos y libertades se halla, de este modo, fundado en un orden político pluralista, acorde con una sociedad abierta. Esta estructura pluralista es la que legitima a los representantes parlamentarios para una concreción y desarrollo legislativo de los derechos fundamentales, acorde con las aspiraciones sociales expresadas por las

5 HÄBERLE, P., Pluralismo y Constitución. Estudios de Teoría Constitucional de la sociedad abierta, ed. a cargo de E. Mikunda, Tecnos, Madrid, 2002, pág. 103. 
mayorías. De igual modo, el propio proceso hermenéutico constitucional actúa como un cauce abierto a las distintas exigencias y alternativas prácticas, es decir, como una instancia crítica capaz de "ponderar los bienes", a fin de resolver y canalizar los conflictos que puedan darse entre los diversos valores e intereses tutelados por la normativa constitucional (vid., sobre ello, las SSTC 101/1983; 32/1985; 163/1991; 30/1993 ...).

La jurisprudencia de nuestro Tribunal Constitucional ha tendido a conjugar, a través del equilibrio y la ponderación interpretativas, los postulados de la unidad y pluralismo en nuestro sistema constitucional de los derechos fundamentales ${ }^{6}$. Una lectura inicial del artículo 139. 1 de la CE, que postula la igualdad de derechos y obligaciones de todos los españoles en cualquier parte del territorio del Estado, así como del artículo 149. 1, que corrobora esta idea al prescribir la competencia exclusiva del Estado en lo referente a "la regulación de las condiciones básicas que garanticen la igualdad de todos los españoles en el ejercicio de los derechos y en el cumplimiento de los deberes constitucionales", podría hacer pensar en la existencia de un absoluto monopolio estatal en la fijación del sistema de los derechos fundamentales. Sin embargo, el alcance de este precepto no es el de consagrar un uniformismo en el régimen de todos los derechos y libertades, sino el de establecer la garantía de su ejercicio en unas condiciones básicas de igualdad. Tesis desarrollada explícitamente por nuestro Tribunal Constitucional al poner de manifiesto que la igualdad de derechos y obligaciones de todos los españoles en cualquier punto del territorio nacional no puede ser entendida "como una rigurosa y monolítica uniformidad del ordenamiento de la que resulte que, en igualdad de circunstancias, en cualquier parte del territorio nacional, se tienen los mismos derechos y obligaciones". Puesto que la potestad legislativa de que las Comunidades Autónomas gozan potencialmente en nuestro ordenamiento tiene una estructura compuesta, "por obra de la cual puede ser distinta la posición jurídica de los ciudadanos en las distintas partes del territorio nacional" (STC 184/1981, FJ2). Doctrina corroborada por una decisión posterior en la que, con respecto a la simultánea articulación de la diversidad de estatutos subjetivos con la unidad del ordenamiento, se establece que: "no es, en definitiva, la igualdad de derechos de las Comunidades lo que garantiza el principio de igualdad de derechos de los ciudadanos ( ... ), sino que es la necesidad de garantizar la igualdad en el ejercicio de tales derechos lo que, mediante la fijación de unas comunes condiciones básicas, impone un límite a la diversidad de las posiciones jurídicas de las Comunidades Autónomas" (STC 76/1983 FJ2). Se desprende de todo ello, que los Estatutos de Autonomía pueden establecer el desarrollo del sistema constitucional de los derechos fundamentales que, respetando las condiciones básicas de la igualdad de su

6 PÉREZ LUÑO, A.E., Derechos humanos, Estado de Derecho y Constitución, cit., pp. 295 y sS.; PRIETO SANCHÍS, L., Justicia constitucional y derechos fundamentales, Trotta, Madrid, 2003., pp. 175 y ss.; VIDAL GIL, E., Los conflictos de derechos en la legislación y en la jurisprudencia españolas. Un análisis de los casos difíciles, Tirant lo Blanch, Valencia, 1999. 
ejercicio (en el sentido de evitar cualquier tipo de privilegio, discriminación o arbitrariedad en su desarrollo estatutario), introduzca modalidades que hagan especial hincapié en aquellos derechos que sean de interés prioritario en su respectivo ámbito territorial. Esta posibilidad tiene especial relevancia respecto a la fijación del estatuto de los derechos económicos, sociales y culturales, cuya eficacia queda supeditada a la existencia de una infraestructura que posibilite su implantación. Ha sido aleccionadora al respecto la experiencia de la República Federal de Alemania, donde las constituciones de los Länder han desarrollado y completado eficazmente el precario estatuto de los derechos sociales contenido en la Grundgesetz. Nuestro ordenamiento constitucional permite articular la unidad básica del sistema de los derechos fundamentales, con el pluralismo de su desarrollo y perfeccionamiento a través de los Estatutos de Autonomía.

\section{Desde la Plenitud a la APertura JuRisdiccional}

Otro de los signos característicos del constitucionalismo actual, con inmediata incidencia en las libertades, es el de una paulatina relativización del postulado de la plenitud del orden jurídico y su desplazamiento hacia la garantía de una multiplicidad de instancias jurisdiccionales tendentes a articular la garantía efectiva de los derechos fundamentales. El carácter completo y pleno del ordenamiento jurídico era corolario de su condición de sistema único y cerrado. Por eso, cuando hoy se afirma la dimensión plural y abierta del ordenamiento, necesariamente se cuestiona el rasgo de su plenitud.

Los ordenamientos jurídicos y, en especial su sistema de fuentes, se han visto directamente afectados por el fenómeno del pluralismo. La superación del ámbito de referencia estatal, producto del nuevo orden de relaciones internacionales, se ha traducido en fuentes que expresan una supra estatalidad normativa. Pero, el desplazamiento del centro de gravedad en el proceso de determinación de las fuentes jurídicas no sólo se ha producido por la aparición de poderes normativos superiores al Estado. De forma paralela, se ha producido una ampliación de competencias normativas por parte de los entes sociales intermedios, situados entre el ciudadano y el poder estatal. Hoy se asiste a un fenómeno de infra estatalidad normativa manifestado en el pluralismo de determinación de fuentes jurídicas. Para aludir a esa situación he utilizado la metáfora del "Desbordamiento de las fuentes del derecho"

En esta nueva coyuntura en la que el ordenamiento jurídico estatal se halla trascendido por otras instancias normativas, aludir a la inexistencia de lagunas en su seno ha perdido gran parte del significado que pudo tener en el periodo histórico anterior como garantía de la seguridad jurídica de los ciudadanos ${ }^{8}$.

7 PÉREZ LUÑO, A.E., El desbordamiento de las fuentes del derecho, cit., pp. 76 y ss.

8 PÉREZ LUÑO, A.E.,. La seguridad juridica, Ariel, Barcelona, 1991, (2. a ed.1994), pp. 30 ss. y 78 y ss. 
En la coyuntura presente se hace especial hincapié en la apertura al procedimiento jurisdiccional, más que a la plenitud del ordenamiento jurídico, como garantía de la tutela de las libertades. Esa tendencia ha hallado eco doctrinal en la obra colectiva, Critical Legal Thought, que vino a ser para los años 90 lo que en la década de los 70 supuso el Congreso de Catania sobre el Uso Alternativo del Derecho. En su contribución a dicha obra, Rudolf Wiethölter ha definido la tarea a cumplir en los años inmediatos por la teoría crítica del derecho, como la "Proceduralización" de las categorías jurídicas?. Esa tarea ha sido concretada, en la propia obra, por Erhard Denninger como un esfuerzo hacia la garantía a través del procedimiento de un equilibrio de posiciones entre los miembros de la sociedad democrática, en las relaciones entre particulares y de éstos con los poderes públicos. Ese status activus processualis, que completaría la teoría de los status elaborada por Jellinek, constituye un factor clave de los Estados de Derecho para asegurar el ejercicio pleno de todas las libertades. Este status procesal se concibe como el reconocimiento de cada persona de participar activamente y asumir su propia responsabilidad en los procedimientos que le afectan, así como en las estructuras organizativas. En el plano de los derechos fundamentales, implica reconocer la apertura a la protección jurisdiccional de las libertades, así como acoger formas de participación dinámicas y activas por parte de los interesados en los procedimientos tendentes a la formación de actos jurídicos ${ }^{10}$.

Haciéndose eco de esa inquietud, ha reconocido nuestro TC que: «Para la ordenación adecuada del proceso existen impuestos, formas y requisitos procesales que, por afectar al orden público, son de necesaria observancia por su racionalidad y eficacia", pero sin que ello suponga aceptar la validez de obstáculos procesales que "sean producto de un innecesario formalismo y que no se compaginan con el derecho a la justicia". (STC, 95/1983, FJ.5. Vid. también en sentido análogo las SSTC, 3/1983, FJ 1; 19/1983, FJ 4; 65/1983, FJ 4). Todavía reviste mayor interés, desde el punto de vista del reconocimiento por nuestra jurisprudencia constitucional del derecho a la jurisdicción, cuanto se afirma en la decisión que proclama: «el artículo 24.1 CE reconoce a todas las personas el derecho a obtener la tutela judicial efectiva de los jueces y Tribunales en el ejercicio de sus derechos e intereses legítimos". El TC entiende que el contenido básico de tal derecho "en un orden lógico y cronológico, es el acceso a la jurisdicción, que se concreta en el derecho a ser parte en un proceso y, como ha declarado este Tribunal Constitucional, poder promover la actividad jurisdiccional que desemboque en una decisión judicial sobre las pretensiones deducidas" (STC 220/1993, FJ2; vid., también las SSTC 115/1984; 15/1985; 34/1989; 164/1991; 192/1992; 28/1993 у 101/1993).

9 "Proceduralization of the Category of Law", en el vol. col. Critical Legal Thought: An American-German Debate, a cargo de Ch. Joerges y D.M. Trubek, Nomos, Baden-Baden, 1989, pág. 501.

10 "Government Assistance in the Exercise of Basic Rights" (Procedure and Organization), en el vol. col. Critical Legal Thought: An American-German Debate, pp. 461 ss. 
En lo que respecta a la tensión entre plenitud y apertura jurisdiccional, los enfoques actuales de las libertades deben inclinarse a una postura mediadora. Cabe demandar a los actuales empeños teóricos y prácticos sobre la significación de los derechos fundamentales un esfuerzo de mediación entre las exigencias, hoy prácticamente inalcanzables, de la absoluta plenitud del orden jurídico y un procedimentalismo entendido como respeto a las garantías procesales y apertura a la jurisdicción que son rasgos informadores de las estructuras jurídicas de las instituciones democráticas.

\subsection{Desde la coherencia a la argumentación}

La coherencia, en cuanto ausencia de antinomias o contradicciones normativas, era una condición fácilmente predicable de los ordenamientos jurídicos caracterizados por las notas de la unidad y la plenitud. Cuando esas notas resultan cuestionadas, al haberse erosionado la dimensión unitaria, compacta, cerrada y autosuficiente de los sistemas jurídicos, y su consiguiente decantación hacia el pluralismo, la apertura y la multiplicidad compleja de su estructura normativa, la coherencia ha devenido una condición prácticamente inalcanzable. Por ello, en los ordenamientos jurídicos de los Estados de derecho del presente resulta casi imposible garantizar la inexistencia de antinomias, y se tiende a sustituir esa garantía de seguridad jurídica por la exigencia de un amplio aparato argumentativo tendente a motivar la racionalidad de las posibles contradicciones existentes entre las normas y/o las decisiones judiciales, que son inevitables en ordenamientos abiertos y complejos.

Si se puede considerar a Peter Häberle como el máximo exponente teórico del pluralismo constitucional, con idéntica razón se debe reputar a Robert Alexy como el más cualificado estudioso del papel de la "argumentación iusfundamental. Alexy, tal como se ha tenido ocasión de apuntar supra, ha prestado especial atención doctrinal a los procesos actuales tendentes a clarificar la teoría argumentativa en el seno de los procesos rehabilitadores de la racionalidad práctica. En su obra sobre la Teoría de la argumentación jurídica, ha llevado a cabo un importante esfuerzo intelectual tendente por sugerir reglas y procedimientos dirigidos a garantizar la racionalidad de la argumentación jurídica. Se pretende evitar, de este modo, que las ineludibles valoraciones del jurista intérprete degeneren en juicios de valor subjetivos y arbitrarios. La referencia a las normas materiales y procesales aplicables al caso, la obligada consideración de los precedentes, así como las pautas orientadoras de la Dogmática jurídica institucionalmente cultivada, constituyen el horizonte en el que se proyecta la racionalidad práctica en el derecho ${ }^{11}$.

Quizás el mérito principal de la investigación de Alexy resida en su esfuerzo por establecer un acercamiento entre la argumentación jurídica a par-

11 Theorie der juristischen Argumentation, Suhrkamp, Frankfurt a.M., 1978, (existe trad. cast. de M. Atienza e I. Espejo, Teoría de la argumentación jurídica, Centro de Estudios Constitucionales, Madrid,1990, pp. 32 y ss. y pp. 263 ss. 
tir de la racionalidad práctica y el análisis lógico y lingüístico del razonamiento jurídico. Alexy comparte con los teóricos de la argumentación la idea de que la racionalidad jurídica no puede reducirse a esquemas de la lógica formal, y rechaza que la interpretación del derecho sea un acto de su subsunción mecánica, tal como se desprende de la actitud metodológica del positivismo legalista. No obstante, entiende que la racionalidad de la argumentación jurídica no deja de ser una forma de "racionalidad", que debe obedecer a premisas de corrección y rigor. El elemento básico para conseguirlo es el procedimiento.

El razonamiento jurídico no responde al azar o a la arbitrariedad, sino a «razones" que actúan como modelos justificativos de la creación, la interpretación y la aplicación de normas. Esas justificaciones no sólo se basan en factores estáticos (la conformidad de las premisas con el contenido de reglas jurídicas positivas o meta positivas - Derecho natural—; o la estricta deducción entre las premisas y sus consecuencias...); sino principalmente en un elemento dinámico: el procedimiento argumentativo ${ }^{12}$.

Robert Alexy ha acogido, desarrollado y proyectado a la teoría del derecho y a los derechos fundamentales las tesis sobre el discurso práctico y la teoría consensual de la verdad debidas a Jürgen Habermas. Según Alexy, un discurso práctico es racional cuando satisface las condiciones de una argumentación práctica racional. Cuando estas condiciones se cumplen, el resultado del discurso es correcto. La teoría del discurso es, por tanto, una teoría procedimental de la corrección práctica. Las condiciones que garantizan la racionalidad del procedimiento del discurso son resumidas por Alexy en un sistema de reglas que guían la actividad de la racionalidad práctica. Estas reglas responden a una doble exigencia: 1) Las que garantizan la corrección estructural de los argumentos y que imponen, entre otras cosas, su no contradicción, la claridad lingüístico-conceptual, la veracidad de las premisas empíricas utilizadas, la exhaustividad deductiva de los argumentos, la consideración de las consecuencias, la valoración comparativa de los argumentos...; 2) Las que garantizan la imparcialidad del procedimiento argumentativo y que hacen referencia al reconocimiento del derecho a participar en el discurso en condiciones de libertad y de igualdad (cualquier persona capaz puede intervenir en el discurso, plantear sus puntos de vista, deseos y necesidades; a ningún dialogante se le puede impedir que ejercite sus facultades reconocidas en las reglas del discurso, mediante una coacción establecida, exterior o interior al discurso $)^{13}$.

Robert Alexy entiende que la argumentación iusfundamental posee algunas peculiaridades respecto a las demás formas de argumentación jurídica. La fundamentación de los derechos en valores éticos y su vinculación con determinadas concepciones y metas políticas, exige que esta forma de

12 Theorie der juristischen Argumentation, cit., pp. 177 ss.

13 Theorie der juristischen Argumentation, cit., pp. 213 ss. 
discurso práctico se atenga a reglas procedimentales que avalen su racionalidad. En la tarea de construir una argumentación iusfundamental que responda a exigencias de racionalidad, corresponde un especial protagonismo a los Tribunales Constitucionales. Alexy concluye que para dotar de seguridad a la argumentación iusfundamental: "es razonable la institucionalización de una justicia constitucional cuyas decisiones pueden y requieren ser justificadas y criticadas en un discurso iusfundamental racional ${ }^{14}$.

Las tesis de Robert Alexy permiten, a mi entender, inferir una doble consecuencia:

1. ${ }^{a}$ Que la teoría de la argumentación iusfundamental ha supuesto, en cierto modo, un desplazamiento desde la hoy cuestionable coherencia del ordenamiento jurídico, a la coherencia, en términos de racionalidad discursiva, de las decisiones jurisprudenciales referidas a los derechos fundamentales.

2. ${ }^{a}$ Que la teoría de la argumentación racional de Alexy no es ideológicamente neutral. Los presupuestos del procedimiento discursivo son la libertad y la igualdad, o sea, los valores básicos del Estado de derecho y a su vez, la teoría del consenso obtenido a través de la argumentación racional constituye el fundamento legitimador de la legalidad del Estado de derecho. De este modo se advierte una cierta circularidad en esta concepción argumentativa de las libertades: la argumentación exige la presencia de determinados derechos para garantizar su propia racionalidad e imparcialidad; y los derechos fundamentales requieren de la argumentación para poder ser interpretados y aplicados a las situaciones concretas.

En la jurisprudencia constitucional española, al igual que en la de otros Estados de derecho de nuestro entorno político-cultural, se advierte el preponderante papel que asume la argumentación como garantía de la seguridad jurídica de los ciudadanos. En el marco de la amplia, casi constante referencia del TC a la fundamentación racional de sus argumentos y en relación con aspectos que inciden en la argumentación iusfundamental, se pueden distinguir tres postulados básicos:

1. ${ }^{\circ}$ La argumentación racional se considera como requisito básico para la tutela efectiva de los derechos fundamentales. Existe una abundante jurisprudencia en la que expresamente se alude a la motivación, en términos de argumentación racional de las decisiones, como elemento nuclear del derecho constitucional a la tutela efectiva. Así,

14 ALEXY, R., Teoría de los derechos fundamentales, trad., cast. de E. Garzón Valdés, Centro de Estudios Constitucionales, Madrid, 1993, pp. 554 
nuestro máximo intérprete de la Constitución proclama que: «Es doctrina reiterada de este Tribunal Constitucional que la tutela judicial efectiva, consagrada en el artículo 24.1 CE, comprende el derecho a obtener una resolución fundada en Derecho, como garantía máxima — dada la esencia de la función jurisdiccional— frente a la arbitrariedad e irrazonabilidad en la actuación de los poderes públiCos" (STC 131/1990,FJ 1.). Doctrina reiterada, entre otras, en la sentencia que sostiene: "La obligación de motivar las sentencias que el art. 120.3 CE impone a los órganos judiciales, puesta en conexión con el derecho a la tutela judicial protegido por el art. 24.1 de la Constitución —entendido como derecho a una resolución jurídicamente fundada-, conduce a integrar en el contenido de esta garantía constitucional el derecho del justiciable a conocer las razones de las decisiones judiciales y, por tanto, el enlace de las mismas con la ley y el sistema general de fuentes, de la cual son aplicación" (STC 14/1991, FJ 2).

2. ${ }^{\circ}$ La argumentación judicial se concibe como un ejercicio de racionalidad tendente a evitar decisiones arbitrarias. Un buen número de sentencias de nuestro TC coinciden en exigir una motivación basada en razonamientos argumentativos de las decisiones judiciales, como medio para evitar resultados contradictorios o ilógicos. Ello implica que los jueces deberán justificar racionalmente sus resoluciones y sentencias. Baste como muestra cuanto el TC expresa en los siguientes párrafos: "Es doctrina reiterada de este Tribunal Constitucional que una aplicación de la legalidad que sea arbitraria, manifiestamente irrazonada o irrazonable no puede considerarse fundada en Derecho y lesiona, por ello, el derecho a la tutela judicial... Así ocurre en los casos en los que ... la resolución judicial contiene contradicciones internas o errores lógicos que hacen de ella una resolución manifiestamente irrazonable por contradictoria y, por ello, carente de motivación" (STC 184/1992, FJ 2).

$3 .^{\circ}$ La exigencia de argumentación racional no garantiza el acierto de la decisión judicial. El TC advierte que el procedimiento argumentativo contribuye a que las decisiones judiciales se elaboren según pautas de racionalidad formal, pero sin que ello necesariamente entrañe que el resultado de esas inferencias racionales represente la justicia material Como ejemplo significativo de esta orientación, puede valer cuanto se indica en la siguiente decisión del TC, en la que se sostiene que «el derecho a la tutela judicial reconocido en el artículo 24.1 CE conlleva el derecho a obtener una resolución fundada en derecho en relación a la pretensión formulada ante el Juez competente, el cual debe aplicar de manera motivada las normas jurídicas aplicables y resolver razonadamente la cuestión que se le plantea, pero el artículo 24.1 CE no garantiza el acierto del órgano judicial en cuanto a la solución del caso concreto" (STC 55/1993, FJ 5). 


\section{CONCLUSIÓN: TRANSFORMACIONES DEL SISTEMA DE LOS DERECHOS FUNDAMENTALES Y CRISIS DEL POSITIVISMO JURÍDICO}

Las consideraciones que anteceden no pretenden propugnar la tesis de la superación de la unidad, plenitud y coherencia de los sistemas jurídicos. Sin una proporción adecuada de tales postulados, un ordenamiento jurídico sería impensable. Pero, con el mismo énfasis con el que se reitera la importancia de esos ingredientes básicos de los ordenamientos normativos, se debe admitir la erosión de las categorías teóricas con que fueron elaborados por el positivismo jurídico formalista.

Los desplazamientos de estos postulados hacia nuevas exigencias y pautas funcionales de los sistemas jurídicos, si no significan su abolición, entrañan transformaciones y cambios de incuestionable calado en su significación y alcance. El positivismo jurídico formalista, en particular su formulación más acabada e influyente, o sea, la teoría pura del derecho de Hans Kelsen, ha sido incapaz de hacerse cargo y de explicar adecuadamente esa metamorfosis. De ello, se desprende la profunda crisis que aqueja a esa versión de la ciencia jurídica y la consiguiente aparición de una multiplicidad de teorías "postpositivistas", que, en muchos casos, implican la abierta negación de los postulados-guía de la teoría pura y la admisión encubierta de determinados presupuestos metodológicos y teóricos muy próximos a concepciones iusnaturalistas ${ }^{15}$.

La unidad, coherencia y plenitud del orden jurídico respondían a una concepción jerárquica de su estructura y funcionamiento. La idea kelseniana de la "norma fundamental" (Grundnorm), evocaba la imagen de una norma suprema y que, por ser la primera, no tenía por encima otra norma superior o previa. Este rango primero o último, según se quiera entender, imprimía a todo el ordenamiento una estricta conformación jerarquizada, en la que a tenor de la célebre teoría kelseniana de la formación del orden jurídico por grados o peldaños (Stufenbau der Rechtsordnung), la validez de cada norma se hacía depender de su estricta vinculación y origen en una norma inmediatamente superior $^{16}$.

En la parte dedicada por Hans Kelsen, en la segunda edición de su Reine Rechtslebre, a la "dinámica jurídica" (Rechtsdynamik), explicitaba su concepción jerárquica del ordenamiento normativo. La construcción por grados o

15 PÉREZ LUÑO, A.E., Los derechos fundamentales, cit., pp. 58 ss.

16 DELGADO PINTO, J., "El voluntarismo de Hans Kelsen y su concepción del orden jurídico como un sistema normativo dinámico" en Estudios en honor del Profesor José Corts Grau, Secretariado de Publicaciones de la Universidad de Valencia, 1977, vol., I, pp. 175 ss.; DELGADO PINTO, J., "Sobre la vigencia y la validez de las normas jurídicas", en Doxa, . 1990, vol. 7., pp. . 101 ss.; GARCÍA AMADO, J.A., Hans Kelsen y la norma fundamental, Marcial Pons, Madrid, 1996, págs. 56 ss.; PÉREZ LUÑO, A.E., Trayectorias Contemporáneas de la Filosofía y la Teoría del Derecho, Grupo Nacional de Editores, Sevilla, 3. ${ }^{a}$ ed., 2004, pp. 49 ss. 
peldaños del sistema jurídico, implica una idea jerárquica del orden normativo en la que cada norma se apoya en otra y sirve, a su vez, de apoyo a otras hasta llegar a la cúspide de esa estructura escalonada donde se halla la norma fundamental (Grundnorm). A tenor de la teoría kelseniana, de cada dos normas pertenecientes a un ordenamiento jurídico se puede decir que la superior precede a la inferior, la cual es la siguiente o consecuente. En dicho orden jerárquico se precisa una norma que no tenga precedente, ni principio y esa norma es, precisamente, la Grundnorm. Todas las restantes normas del ordenamiento son consecuencia de ella y, al propio tiempo, de la validez de esa norma fundamental se deriva la de las normas que le están subordinadas ${ }^{17}$.

La dinámica jurídica se estructura, según Kelsen, como un todo ordenado, es decir, como un sistema cuyos elementos integrantes o normas forman un conjunto jerarquizado en función de un principio básico que es la norma fundamental. En su obra póstuma Allgemeine Theorie der Normen, Hans Kelsen, al explicar la problemática lógica del fundamento de la validez jurídica ( $L O-$ gische Probleme der Geltungsbegründung), señala que el orden sistemático del derecho se estructura a partir de la validez, entendida como pertenencia al sistema. Lo que significa que cada una de las normas singulares exhibe la cualidad de la validez como rasgo distintivo de su integración y pertenencia al ordenamiento jurídico. En función del principio de validez, las normas que conforman los sistemas jurídicos, quedan ordenadas de forma que las inferiores se fundan en las superiores, hasta llegar a la norma fundamental. Esta concatenación normativa se concreta, en definitiva, en que la validez de las normas inferiores es inconcebible sin la validez de las superiores y, en última instancia, sin la fuente de toda validez del ordenamiento que es la que fluye de la Grundnorm ${ }^{18}$.

De no existir un fundamento último o un término en la concatenación normativa, todo el sistema quedaría vacío de validez. En la concepción kelseniana del ordenamiento jurídico, la Grundnorm desempeña esa función de principio de validez, del que ésta fluye e informa a todas las restantes normas integradoras del sistema; se trata del principio que va a determinar que todas ellas sean válidas.

La "nomodinámica" kelseniana implicaba, en definitiva, una visión jerarquizada del ordenamiento jurídico, que permitía explicar y conjugar sus tres notas o postulados básicos. La unidad, en cuanto que tal ordenamiento se concebía como una entidad indivisa, compacta y enteriza, cuyo rasgo constitutivo identitario (validez) se transmite a cuantos elementos singulares (normas) la integran. La plenitud, en cuanto que esa estructura sistemática en que el ordenamiento consiste aparecía como un todo completo y cerrado, que no admitía fisuras, hiatos o vacíos, es decir, lagunas en el seno de ese conjunto

17 KELSEN, H., Reine Rechtslehre, Franz Deuticke, Wien, 2. ${ }^{a}$ ed. 1960, pp. 198 ss.

18 KELSEN, H., Allgemeine Theorie der Normen, ed. a cargo de K. Ringhofer y R. Walter, Manzsche Verlag-und Universitätsbuchhandlung, Wien, 1979,pp. 203 ss.; vid., también cuanto expone en KELSEN, H.,. Reine Rechtslehre, cit., pp. 196 ss. y 228 ss. 
normativo. La coherencia, a su vez, era también corolario de esa totalidad normativa jerarquizada e imbricada, cuya sistematicidad resultaba inconciliable con cualquier tipo de contradicciones o incompatibilidades (antinomias).

En el interesante intercambio epistolar mantenido por Hans Kelsen con Ulrich Klug, entre los años 1959 a 1965, sobre los aspectos lógico-formales y sistemáticos de la teoría pura del derecho, se explicitan y desarrollan algunos de los aspectos aquí apuntados, en relación con la estructura jerárquica del ordenamiento jurídico y sus consecuencias en orden a la validez normativa ${ }^{19}$.

Esta explicación teórica del ordenamiento jurídico constituyó la expresión formal más brillante, acabada e influyente del positivismo jurídico, en la medida en que, en las décadas anteriores, era un marco explicativo adecuado para reflejar la estructura y funcionamiento de los sistemas jurídico-positivos vigentes. Como quiera que las notas básicas conformadoras de los sistemas jurídicos del presente han sufrido una profunda metamorfosis, cuyos aspectos principales en el ámbito del sistema de los derechos fundamentales han sido objeto de las reflexiones que anteceden, se plantea ahora la cuestión insoslayable de la aptitud de la teoría pura del derecho para dar cuenta de esas mutaciones.

La morfología del ordenamiento jurídico, inferida de la concepción kelseniana, evocaba la imagen de una pirámide o estructura piramidal, cuyo vértice venía constituido por la Grundnorm. Frente a esa representación, el actual significado de los sistemas jurídicos reclama una simbolización que se aproxima más a una bóveda que a una pirámide. Esa estructura abovedada implica la confluencia, involucro o interacción de un conjunto de arcos o cubiertas esféricas, que cierran el espacio comprendido entre muros o columnas. Los actuales desplazamientos desde la unidad al pluralismo, desde la plenitud a la apertura jurisdiccional y desde la coherencia a la argumentación, a cuyo análisis se ha atendido supra, en la esfera del sistema de libertades, inducen y avalan ese nuevo enfoque.

El jurista de la hora presente, habituado a la circunferencia del horizonte explicativo tradicional conformado por la teoría pura del derecho, no acierta ahora a encajar en esa perspectiva del positivismo jurídico el nuevo significado de los ordenamientos normativos. Si hasta el presente la teoría jurídica iuspositivista había padecido un exceso de concentración en un punto de gravitación único y jerárquico (Grundnorm), hacia el cual se hacían converger todos los procesos normativos, a partir del presente deberá acomodar su óptica de enfoque hacia unos ordenamientos jurídicos policéntricos. Esta nueva perspectiva metodológica para asumir el significado actual de los sistemas jurídicos, denuncia la crisis del iuspositivismo kelseniano. Impone sustituir la imagen piramidal, es decir, jerarquizada del orden normativo, por un horizonte en el que la totalidad del sistema se obtendrá por la intersección de una

19 KELSEN, H., KLUG U., Rechsnormen und logische Analyse. Ein Briefwechsel 1959 bis 1965, Franz Deuticke, Wien, 1981. 
pluralidad de estructuras normativas, de procedencia heterogénea y que hacinadas formarán un panorama del ordenamiento jurídico bastante parecido a una bóveda.

No huelga advertir, al concluir estas reflexiones, que los riegos propios de cualquier criterio teórico o metodológico de la ciencia jurídica, se acrecientan cuando se trata de explicar categorías o cuestiones contemporáneas. En este caso, la dificultad de tener que reducir a conceptos la realidad problemática, heterogénea y cambiante de la experiencia jurídica, se ve acrecentada por la necesidad de afrontar unas circunstancias in fieri, que se están haciendo y que, en modo alguno, pueden considerarse una experiencia concluida. El filósofo o teórico del derecho que intenta dar cuenta de las transformaciones que se están produciendo en el presente, realiza una forma de ursprüngliche Geschichte, en la acepción hegeliana, en la que tiene a su favor el ser, a la vez, cronista y actor de hechos de los que le es dado poseer una vivencia directa o inmediata, pero, como contrapartida, carece de la seguridad que proporciona el distanciamiento. De ahí, que las consideraciones aquí avanzadas sobre la crisis del iuspositivismo, en función de la metamorfosis operada en los sistemas jurídicos actuales y, en particular, en el sistema de los derechos fundamentales, ha pretendido solo trazar un marco referencial de orientación de tendencia, más que un esquema rígido, completo y definitivo.

ABSTRACT. This essay studies the aspects that have contributed to the crisis of the theory of the fundamental rights inspired by the juridical positivism. The legal systems and, in particular, their normative sources, have been directly affected by the phenomenon of prevail of the state's monopoly of creation of juridical norms. A deep change has been verified inside the legal systems that has been translated into a triple displacement: from the unit to the pluralism; from the fullness to the jurisdictional opening; and from the coberence to the argument. In this work these new phenomena and their repercussion are analyzed for the freedoms. 